\title{
Vernacular farm buildings in landscape planning: a typological analysis in a southern Italian region
}

\author{
Pietro Picuno
}

School of Agricultural, Forestry, Food \& Environmental Science, University of Basilicata, Potenza, Italy

\begin{abstract}
Farm buildings play a central role in the environmental characteristics of agricultural land. Over the centuries they have accompanied the development of the agricultural activities of man who has thereby been able to breed cattle, to grow and yield crops, and to store, transform and process agricultural products in a functional and efficient way. Farm buildings have allowed man to work in intensive conditions unaffected by the external climate. On the other hand, constructions built by farmers marked their territory, influencing and steering the spontaneous development of nature while leading to production that enabled man to get food. In the present paper, a typological analysis of farm buildings was conducted with reference to the Basilicata region, a southern Italian region rich in a history and culture connected with its traditional agricultural vocation, where rural houses still remain as witnesses to the social and cultural changes that have taken place over the years. Vernacular farm buildings, synthesizing in their architectural expression the culture, traditions and ways of life of generations of rural populations, were identified, analyzed and typologically classified all over the regional land. The results showed that many of the vernacular farm buildings visited are now abandoned; the technical survey often showed a situation of structural and functional degradation that makes their restoration difficult and expensive. Possible ways of reuse, making their recovery more economically profitable are, therefore, analyzed and discussed.
\end{abstract}

\section{Introduction}

Farm buildings are one of the most intriguing examples of original technical and scientific design: conceived to host biological productions, there is no other comparable example in the wide epistemological sector of building construction. The birth, growth and development of living vegetal or animal organisms contained inside these volumes raise architectural and technical issues that are completely different to those of other building sectors. Aimed at producing optimal environmental conditions for plants and animals, while at the same time protecting the hygiene and health of workers involved in the daily operations of the care of living organisms at different stages of their development, the rural building constitutes a unique and unrepeatable technological model.

Indeed, the originality of what happens inside the farm buildings corresponds to what happens outside. The role that the buildings have historically played is strictly connected with the surrounding environment, due to the need of the farmer to live in close contact with agricultural land and animal husbandry. While the organization of human beings involved in the activities of the industrial or tertiary sector allowed aggregation in urban centers, the need to live in constant contact with the agricultural production developed a synergetic function of close proximity to the extra-urban land. This led to the spread in rural areas of many examples of buildings that served for farming, storage and processing of agricultural products constituting, at the same time, housing for the farmer and his family (Van der Vaart, 2005; Dal Sasso and Caliandro, 2010). This form of settlement has been, and still is, a unique way by which humans have populated, in harmony with the natural elements, the agricultural land, joining the agricultural production needed for human nutrition with the control and care of extraurban land (García-Esparza, 2010). Therefore, the interventions made by man have often strongly influenced the agricultural environment and the visual perception of its landscape (Hernández et al., 2004; Picuno et al., 2011)

As in many cases all over Europe, and more specifically in the Mediterranean area, in southern Italy these factors led over the centuries to the construction of many buildings that were designed to fulfil their primary agricultural role, and that now constitute a widespread heritage of irreplaceable architectural value, that should be given the highest consideration during the process of landscape planning (García and Ayuga, 2007). In order to verify the typological characteristics, building condition and status of use of rural buildings, a survey was conducted in order to identify the most popular features of these buildings located in the Basilicata region, an Italian region (Figure 1) characterized by traditional agriculture, whose heritage of vernacular farm buildings has been analyzed in the past by Franciosa (Franciosa, 1942). In the 1940s, Franciosa classified the farm buildings widely distributed throughout the region mainly based on their altitude and their constructive characteristics, with particular attention to the meteorological conditions. This also had a significant influence on the bioclimatic properties of the building, which were con- 
ceived and realized on the basis of exploiting natural factors (i.e. sun, wind, etc.). The value of this research is clear to anybody who loves the traditional landscape and acknowledges, among the different traditional types, the characteristics of the regional cultures. By describing vernacular farm buildings with tower houses, or rural buildings belonging to small landlords (in other words, by defining the typical settlements scattered around the countryside) the author illustrated people's hard living conditions.

Bioclimatic design, showing years of embodied experience built on the relationship between building and climate, satisfies the needs of human beings (heat, light and sound) by focusing on a holistic approach that considers the role of the external environment (Vissilia, 2009). As observed by Coch (1998), modern buildings, clad in glass as a symbol of their modernity, are incongruously dark and require artificial lighting during the day, while the flimsy casing separating them from the outside makes it necessary to use air conditioning all year round, even when outside temperatures are mild. These buildings are so badly built that they produce worse conditions than the climate. Bioclimatism is currently being analyzed by many scientists all over the world (Labaki and Kowaltowski, 1998; Ratti et al., 2003; Singh et al., 2009) as the way that was used in the past to ensure sound climatic conditions for inhabitants through simple building processes based on the exploitation of natural factors such as external climatic conditions, site topography, etc. In some cases (Cañas and Martín, 2004), bioclimatic architecture was also proposed as a new model for rediscovering vernacular construction.

\section{Materials and methods}

The Basilicata region covers a total surface area of almost 10,000 $\mathrm{km}^{2}$ and has a population of approximately 610,000 inhabitants distributed around the two provinces of Matera and Potenza (Figure 2). According to the most recent available statistical data (ISTAT, 1991), in this region more than 11,000 farm buildings have been found; their breakdown by age of construction is shown in Table 1. More than one farm building per $\mathrm{km}^{2}$ is, therefore, present as a mean all over the region.

In Table 1 we see that the number of houses dating back to the early $20^{\text {th }}$ century is not as high, reflecting the fact that at that time there were few owners due to the form of land ownership (latifundium, i.e. large estate), with workers probably coming from small towns nearby. The traditional agricultural vocation of the Basilicata region was, in fact, fostered during the reconstruction period which happened at the beginning of the $20^{\text {th }}$ century. This was also facilitated by financial assistance from the central state, and structures aimed at supporting the rural activities were strengthened through the construction of reservoirs, collective irrigation systems, etc. Then, following the general trend of industrialization in the early 1970 s, the workers were drawn to other, more profitable activities (i.e. industry, service industries), so an exodus from the countryside began, even in areas where government interventions were substantial.

The typological analysis carried out in the present work was conducted on the basis of previous experiences (Franciosa, 1942; Manera et al., 1990). While Franciosa's studies were conducted during the 1940s, aimed at classifying traditional building typologies all over the Italian regions, the need to record the style and consistency of the regional landscapes was backed by more recent studies by Manera et al. (1990) who conducted a specific typological analysis of lodgings in the Basilicata region, containing systematic know-how and accurate reflections. The most representative rural buildings were surveyed with terrestrial photogrammetry and suitable topographic methods for the determination of the support coordinates of control points. These sur-

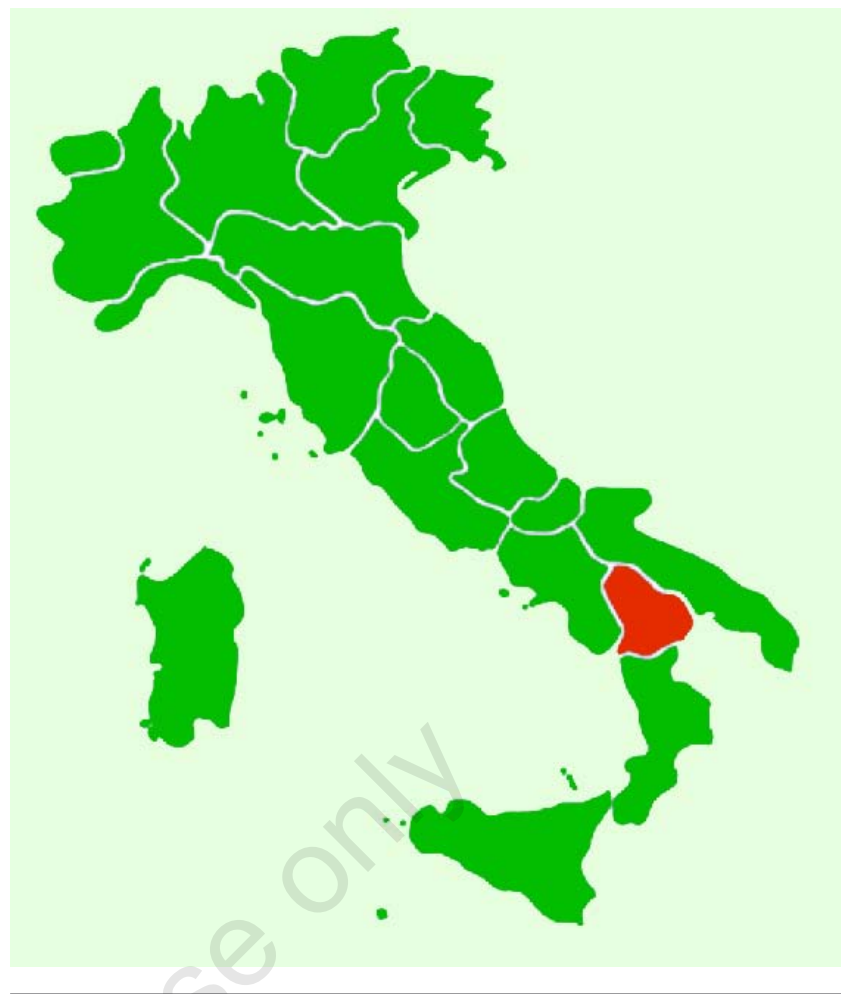

Figure 1. Basilicata Region (in red).

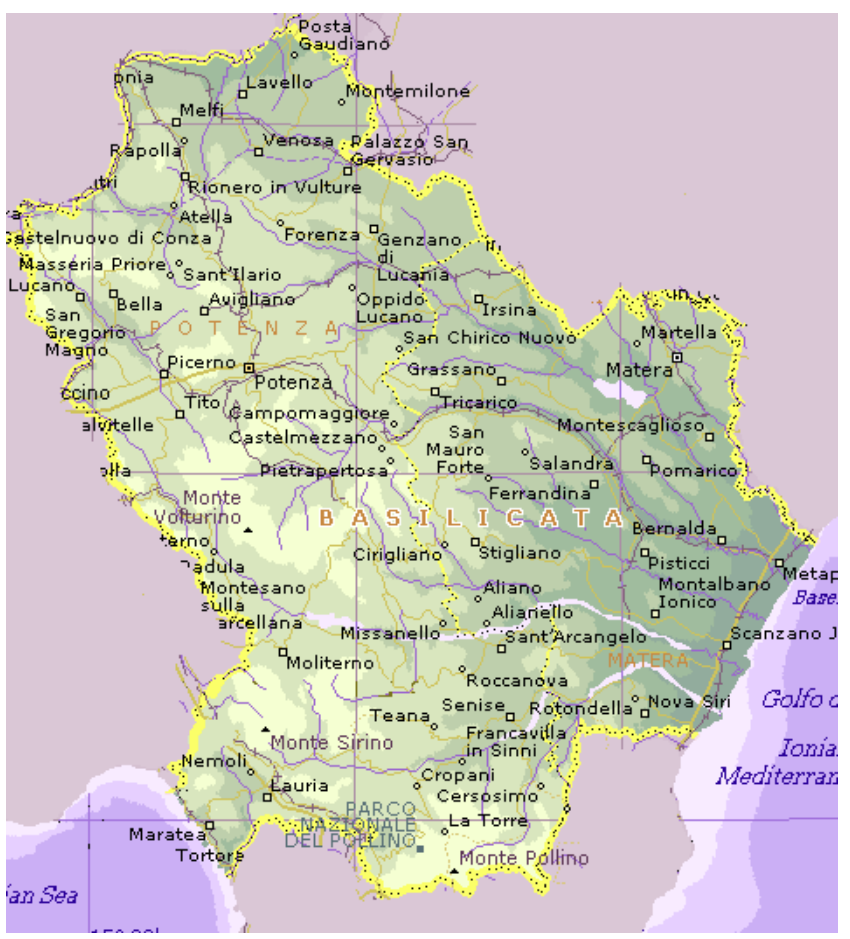

Figure 2. Map of the Basilicata Region. 
vey techniques proved to be very useful in the case of buildings that were high and difficult to survey with conventional methodologies. So, lodgings located in the region that were more attractive from an architectural, historical and cultural point of view were found, and their restoration and reuse as containers for cultural purposes, such as agricultural tourism or as new manufacturing facilities, was finally proposed and discussed. Based on these previous studies, a classification based on Franciosa's analysis (http://www.unibas.it/ruraliasudorientale/regioni/bas/dimore.html) has been adopted here in order to set up the typological analysis that was performed, classifying the vernacular farm buildings in the categories reported in Table 2. In this way, a methodological tool, suitable for a quantitative allocation of the number of units in each category that in future research could be systematically performed was, therefore, established. The distribution of the total number of buildings reported in Table 1 according to the categories of Table 2 is rather difficult, due to the scattered distribution of these buildings all over the region and the different construction dates. As a rough estimate, the historical buildings (before 1919) located in the province of Potenza (about 1000) are quite evenly distributed in the five categories A.1, A.2, A.3, B.1 and B.2, typical of mountainous or high, hilly areas. On the other hand, the corresponding old buildings (more than 300) located in the province of Matera are included in the category B.3, typical of plain or low, hilly areas.

\section{Results}

The analysis has confirmed the main role played by altimetry in characterizing different architectural types: mountainous and high hilly areas are in fact recurring types of lodging characterized by a simple construction, often on one floor. Conversely, in areas at lower altitudes or near the coast, rural housing, also known by the traditional name of Masseria, is expanding, in many cases including, in addition to the main house of the owner, the residences of the settlers and the structures used for livestock production or processing of agricultural products. The forms in this case often show a rare and refined style, adopting more complex and refined architectural solutions.

\section{Typologies A.1, A.2, A.3}

The lodgings of a basic type, whether in hills or mountains, are abandoned or used as shelters for seasonal breeding. Among the temporary housing in mountainous environments, most rural huts and caves are located in the province of Potenza at altitudes higher than $1000 \mathrm{~m}$. They usually show (Figure 3) a structural and functional degradation that, in some cases, is unfortunately advanced.

Separate shelters for the home help or used on a seasonal basis can also be found along the mountainous or hilly areas near the valleys of the rivers crossing the region, as in the case of the unitary mountain form of Guardia Perticara (Figure 4) located along the valley of the Agri river, and the unitary hilly form of the Cascino at Senise (Figure 5), along the valley of the Sinni river.

\section{Typology A.4}

The buildings classified into this typological unit are often located in areas at a lower altitude, organized in basic forms of a compact type. Small buildings, characterized by a very simple architectural typology

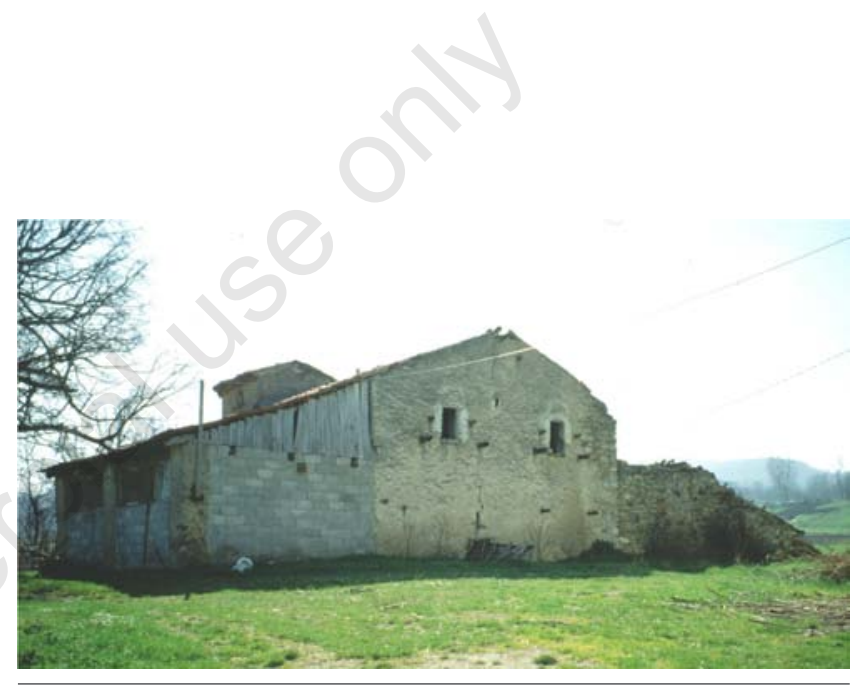

Figure 3. Rural hut located in the province of Potenza.

Table 1. Rural buildings in the two provinces (Matera and Potenza) of the Basilicata region; classified based on when they were built.

\begin{tabular}{lccccccccc} 
& & \multicolumn{9}{c}{ Building construction date } \\
Province & Before 1919 & $\mathbf{1 9 1 9 - 1 9 4 5}$ & $\mathbf{1 9 4 6 - 1 9 6 0}$ & $\mathbf{1 9 6 1 - 1 9 7 1}$ & $\mathbf{1 9 7 2 - 1 9 8 1}$ & $\mathbf{1 9 8 2 - 1 9 8 6}$ & After 1986 & Total \\
Matera & 343 & 413 & 1990 & 576 & 482 & 111 & 114 & 4029 \\
Potenza & 1014 & 957 & 2264 & 999 & 812 & 648 & 732 & 7426 \\
\hline Total Region & 1357 & 1370 & 4254 & 1575 & 1294 & 759 & 846 & 11.455 \\
\hline
\end{tabular}

Table 2. Classification of rural buildings of the Basilicata region according to Franciosa (1945).

\begin{tabular}{|c|c|c|c|c|}
\hline No. & Typology & Sub-typology & Geographical area & Location \\
\hline A.1 & Temporary housing & Rural huts & Mountain & Potenza Province \\
\hline A.2 & Temporary housing & Caves & Mountain & Potenza Province \\
\hline A.3 & Temporary housing & Separate shelters for daily or seasonal stay & Mountain/hill & Potenza Province \\
\hline A.4 & Temporary housing & Simple building for daily or seasonal stay & Plain areas after land reclamation & Metapontino plain \\
\hline B.1 & Specific forms of management & Colonial type & Hill/plain & $\begin{array}{l}\text { Vulture-Melfese area } \\
\text { Lavello } \\
\text { Rionero }\end{array}$ \\
\hline B.2 & Specific forms of management & $\begin{array}{l}\text { Casini holiday } \\
\text { Small fortress }\end{array}$ & Hill/plain & $\begin{array}{l}\text { Vulture-Melfese area } \\
\text { Maratea }\end{array}$ \\
\hline B.3 & Specific forms of management & Farms of composite structure & Plain & $\begin{array}{l}\text { Matera Province } \\
\text { Metapontino plain }\end{array}$ \\
\hline
\end{tabular}


(Figure 6), were built during the first decades of the $20^{\text {th }}$ century in order to host tenants drawn to the incentivate farming of new agricultural fields obtained by a massive land reclamation (the so-called Reform Program) which was implemented in order to rehabilitate a wide area that during those years was affected by malaria. The Reform

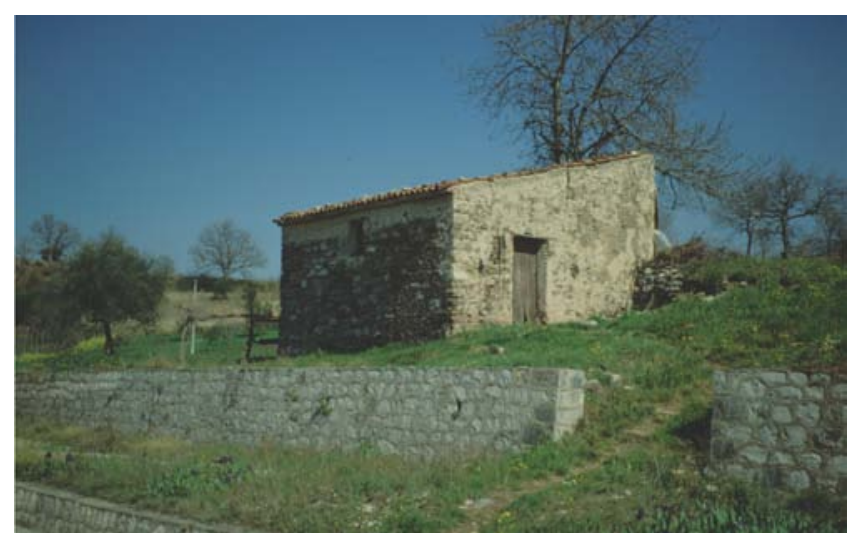

Figure 4. Temporary unitary mountain form located in Guardia Perticara.

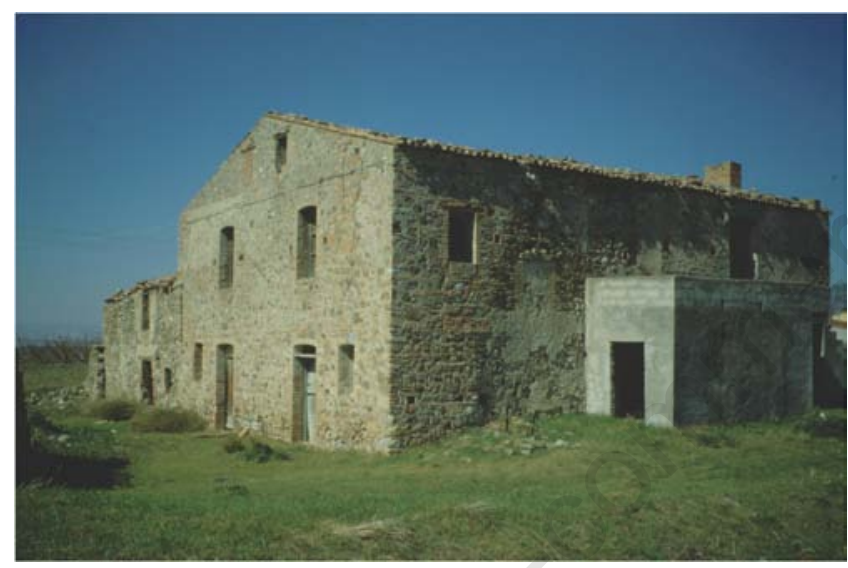

Figure 5. A unitary hill form: the Cascino located in Senise.
Program was to a large degree based on and directed towards farming; in view of this, the problems connected with carrying out the projects in the zone of installation were considerable. The nature of the surroundings in the different agricultural zones was the fundamental guiding criterion in the placement of the dwellings. Technical reasons were also decidedly in favor of scattered dwellings, a system that might be said to be a general rule in agricultural residential structure in Italy. However, and taking into account the dimension of the farms, it was seldom possible to construct more than four houses in one place. In these houses, certain services (such as the oven and the well) were shared. Only in those cases where particular circumstances tended to render excessively difficult the scattered dislocation of the farmhouse were these grouped, sometimes in notable quantities, close to the farms. The reasons for this lie for the most part in the water supply for domestic use, the nature of the soil, the slope of the land, and the bad conditions of the byroads.

The types of farmhouses built for the farmer and his family were composed of an average of three working units, that being the minimum number required for the dwelling, shelter for the animals, and cover for the farm equipment. The prevailing type has a single storey, both for reasons of cost and of the widespread traditional usage in the Basilicata region and in the neighboring Apulia region. Houses with two storeys have been built in some low-lying zones of the Metaponto area, close to the Ionian seaboard strip. Each farm unit is furnished with an oven, a pigsty, a chicken yard and a manure pit situated at a convenient distance from the dwelling, integrated with the silo and the sheepfold.

Building materials have been adapted to the traditional materials found in the various zones. Therefore, tufo (tuff) is used predominantly, because of the large quantity of this material found in the surrounding hilly areas of Murgia and along the Ionian coast (the areas of Middle Tarantine, Arneo and Salento). In general, the foundation walls have been realized with conglomerate concrete or with reinforced concrete, this latter in those predominantly clay zones so frequent in this area. In order to isolate the walls' structure from the humidity of the soil, asphalt or tar paper was used on the upper parts of the foundations. Rainwater drainage, and its running off into the water cistern, is achieved by means of a galvanized iron or fibre-cement drainpipe with cast-iron fittings.

The historical aggregates of Policoro and Scanzano Jonico and the rural villages of Andriace, Recoleta and S. Basilio, present in the Metaponto coastal strip, are characterized as feudal estates, later surrounded by small scattered houses (casalini) used for permanent or

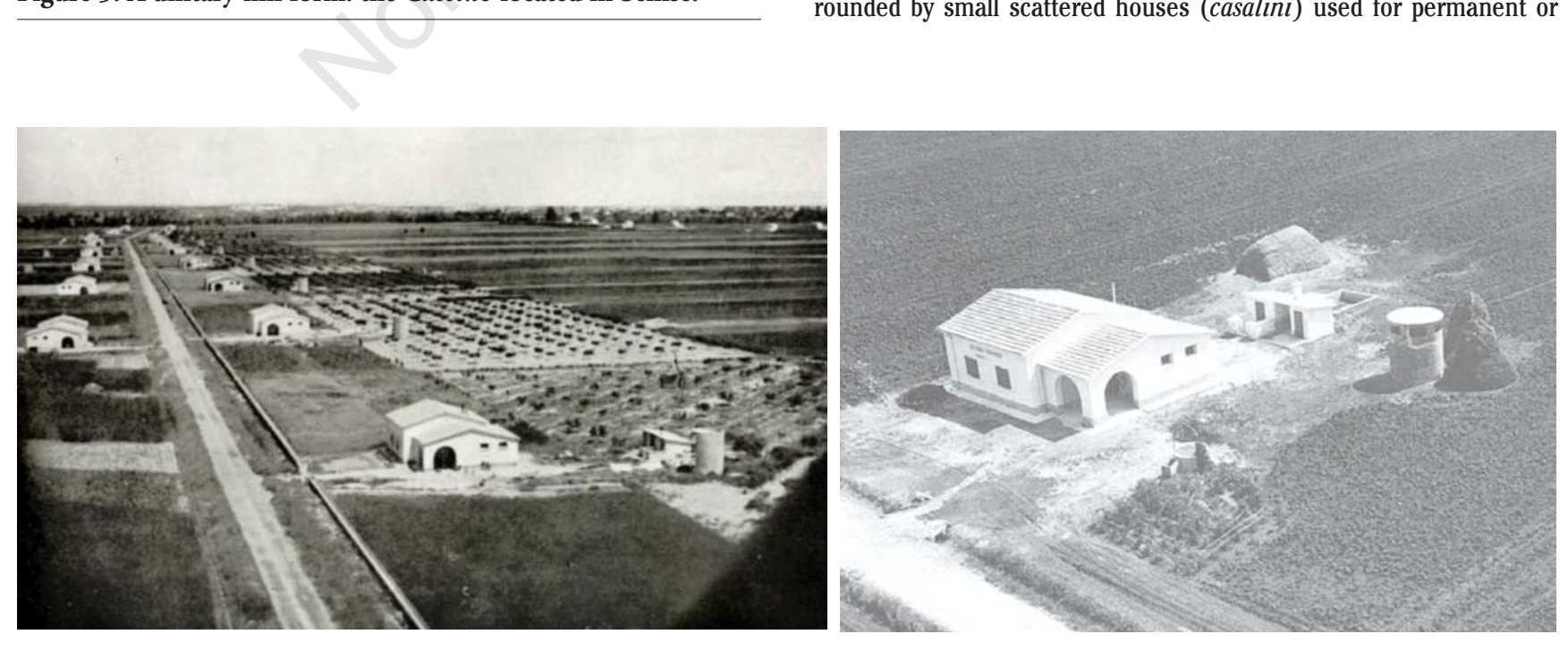

Figure 6. Simple building in the Metapontino Plain area after land reclamation. [Source: http://www.unibas.it/herodot/home.htm] 
temporary housing of the agricultural workers. In the hilly parts of this district are the three major centers of Pisticci, Montalbano Jonico and Bernalda, where rural dwellings, unlike those of the flat area, are characterized as a unit with one room on the ground floor, or on two floors with a kitchen usually on the first floor and an external staircase.

Since in the Reform area the towns were often far apart, it was impossible to create a new settlement without all the necessary civil and social services common in such situations. As a consequence, it was sometimes necessary in one or other of the towns to construct public buildings of notable importance (rural centers) to serve as frameworks around which future rural villages could be built. In territories where new settlements were of a sporadic nature, several service centers of smaller dimensions were constructed.

\section{Typology B.1}

Lodgings of a basic type, but of greater architectural value and a greater emphasis on style are found in the north-eastern area of the Basilicata region, where an external staircase can frequently be found. This is the case of the farm located in Irsina (Figure 7) and of the Masseria Giannini farm (Figure 8) located at Monticchio Lakes in Rionero, in the Vulture-melfese Park area. In this last case, the architectural typology is classifiable as Marchigiana due to its characteristic of reproducing stylistic forms of the houses of the Marche region (fur- ther north), since the owners wanted to create for the settlers from the Marche an environment similar to their own. Typical of this form of rural residence is the presence outside the building of a perron for gaining access to the upper floor.

Similar examples may be found even along the coast of the Tyrrhenian Sea, for example, the Marateino typology, a colonial farm located in San Nicola di Maratea. This valuable building shows (Figure 9) a half-covered porch and perron.

\section{Typology B.2}

In the lower part of the Agri Valley, farm buildings are often equipped with small towers (Figure 10). These particular structural elements, usually built as dovecotes, could also have performed different roles during wartime. Due to the frequent battles among different feudal lords, and between them and their vassals, the farmhouse, in fact, turned into a real fortress which had to ensure their safety against invaders or the brigands who infested the territories. Therefore, the house was built with a small tower, equipped with loopholes, secret exits and shelters in which the owner and his family could hide.

Similar examples, even more refined in their architectural concept, can be found elsewhere in the same area, as in the case of the farm located in Marsico Nuovo (Figure 11).

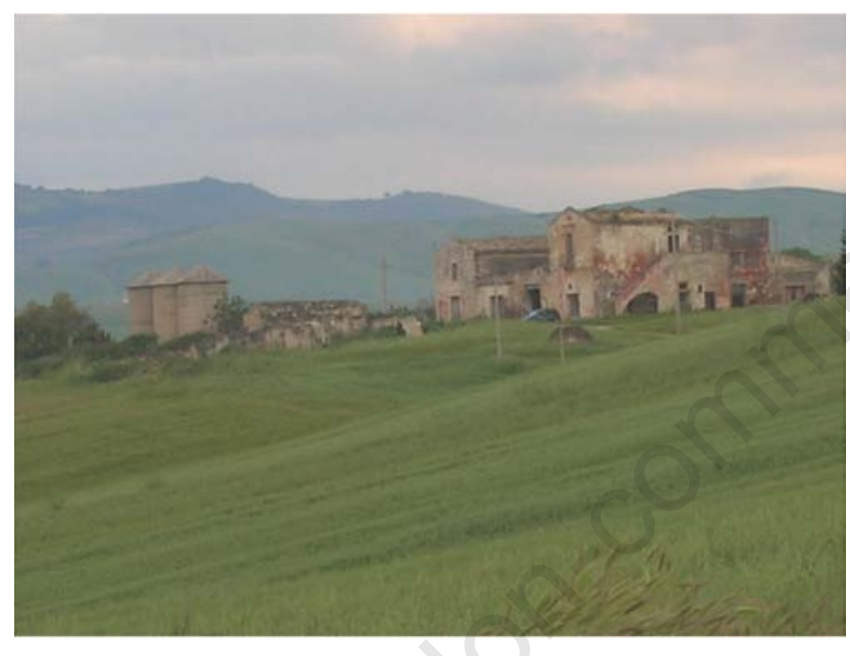

Figure 7. Masseria with external stairs located in Irsina.

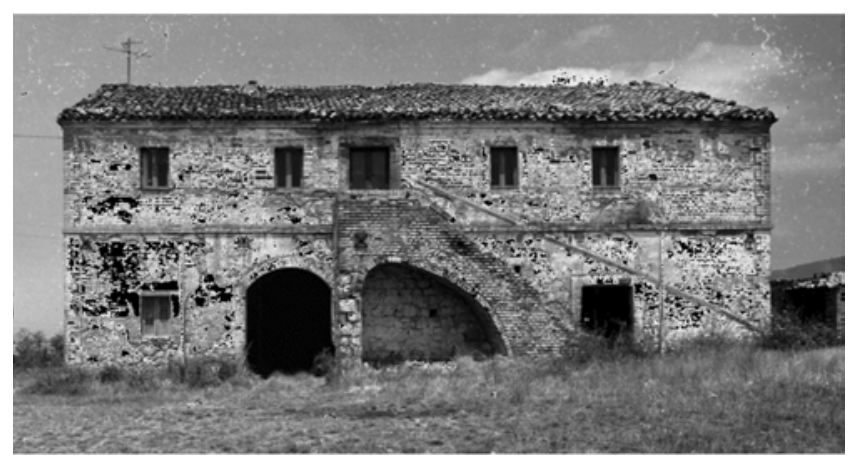

Figure 8. Masseria Giannini located at Monticchio Lakes (Rionero). [Source: http://www.unibas.it/ruraliasudorientale/ regioni/bas/masserie/giannini.html]

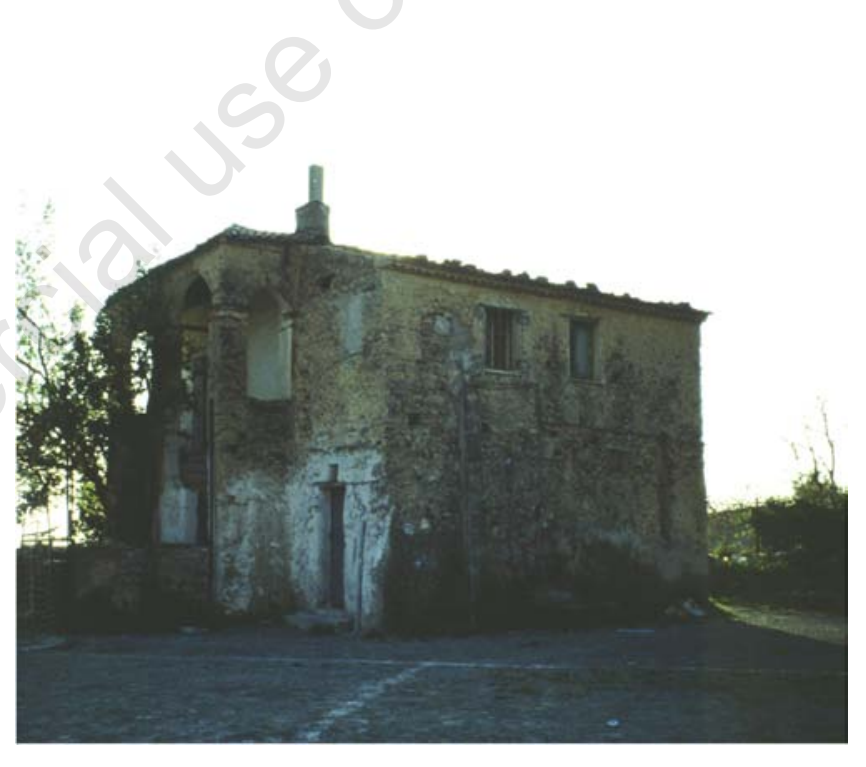

Figure 9. Masseria San Nicola di Maratea located in Maratea.

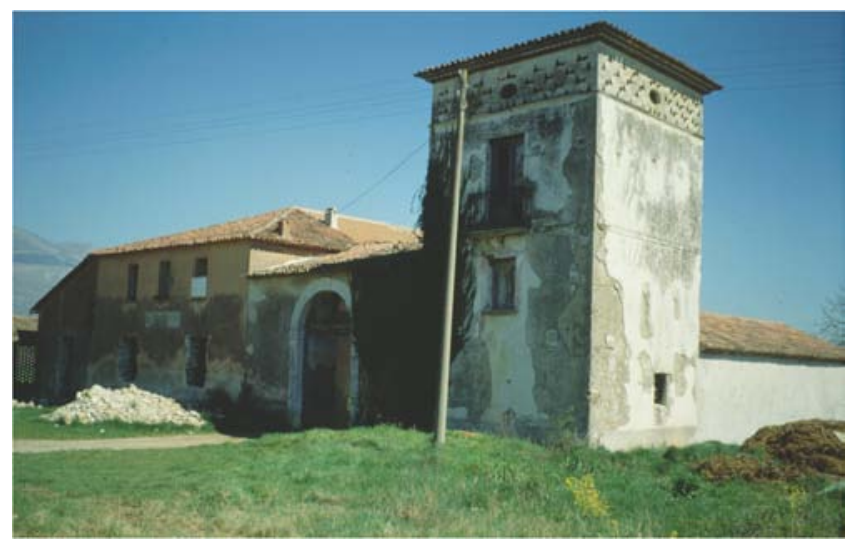

Figure 10. Farm with a tower located along the Agri River Valley. 


\section{Typology B.3}

In the plain of Metaponto, on the Ionian sea, the large farm prevails in the form of a village or small town, where the house of the landowner or tenant is clearly separate from the cottages and the houses of permanent and temporary employees. The house of the landowner is of vast proportions, with a majestic appearance and consisting of at least three floors. It rises mainly isolated from the other buildings, although there may be some buildings in the vicinity. Among these buildings is the Berlingieri Baronial Palace of Policoro (Figure 12). The building stands on a hill with a large internal cloister; it consists of three floors, and the access is through a large gate and interior staircases. On the roof is the square tower lookout point. The rooms on the ground floor were utilized for various purposes (such as grain warehouses, stables, or storages for machines and the personal tools of the tenants). The rooms on the first floor constituted the house of the tenants; the last floor was reserved for the landowner.

All along the Ionian coast there are farms of a complex type, with the

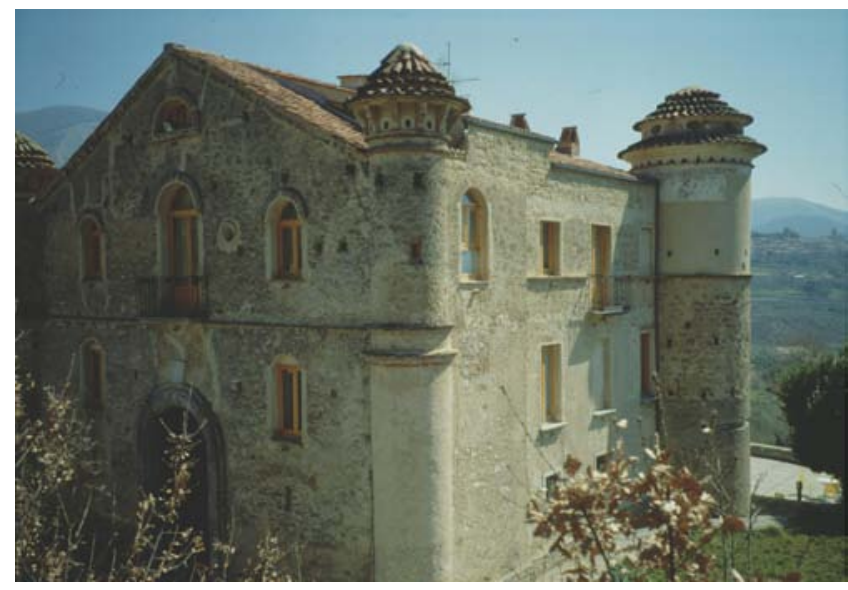

Figure 11. Masseria with small towers located in Marsico Nuovo.
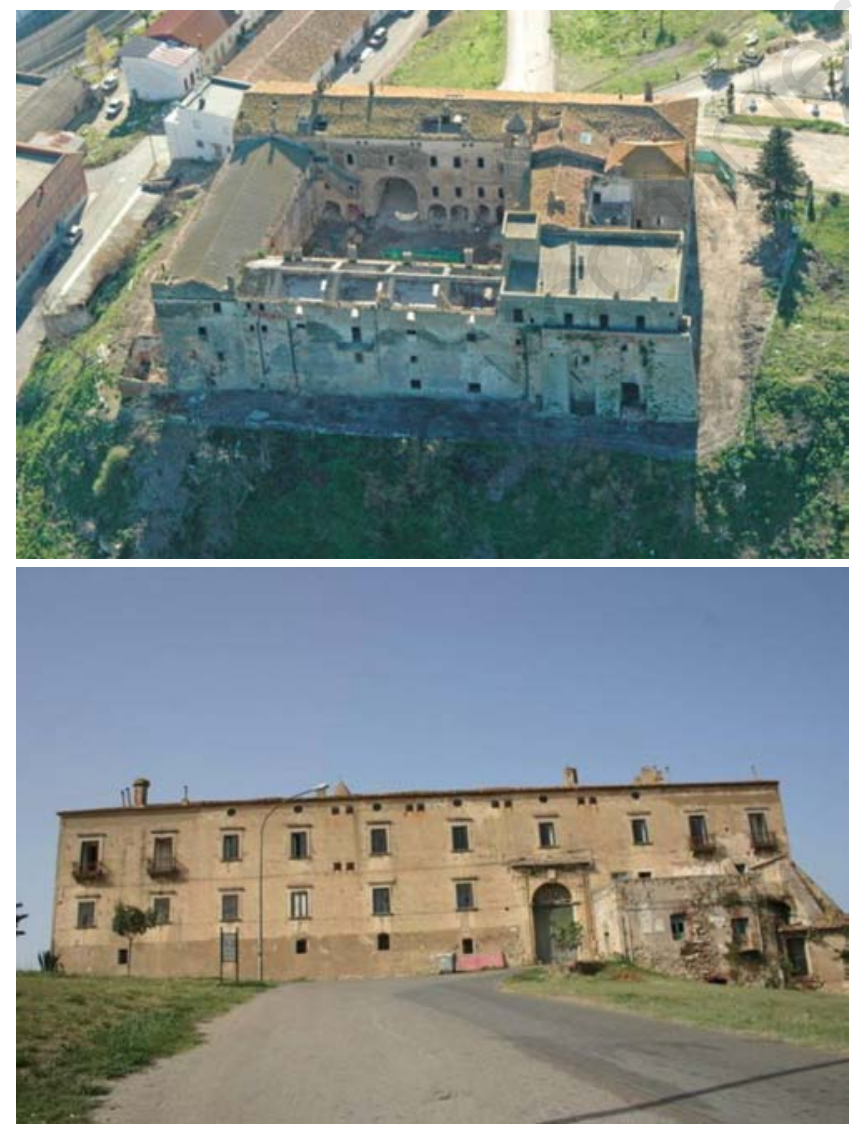

Figure 12. Berlingieri Baronial Palace located in Policoro.

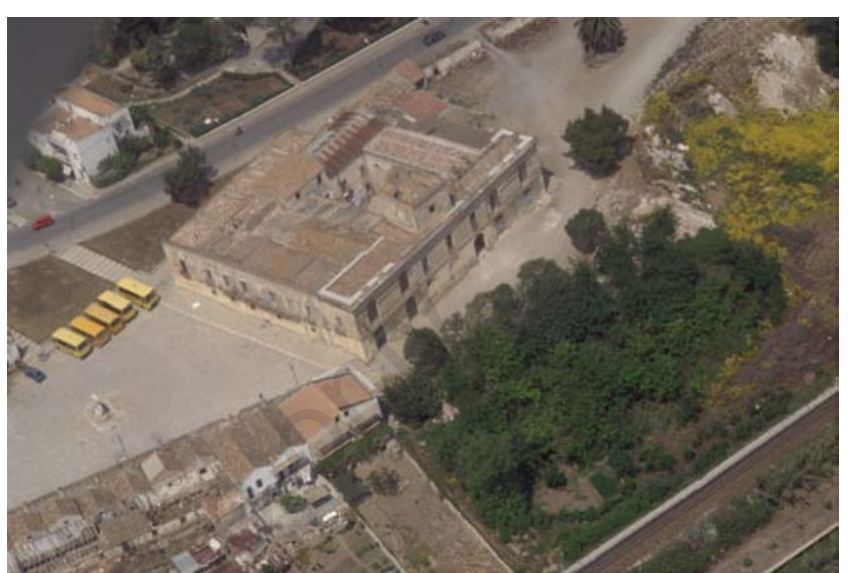

Figure 13. Palazzo di Scanzano located in Scanzano Jonico.
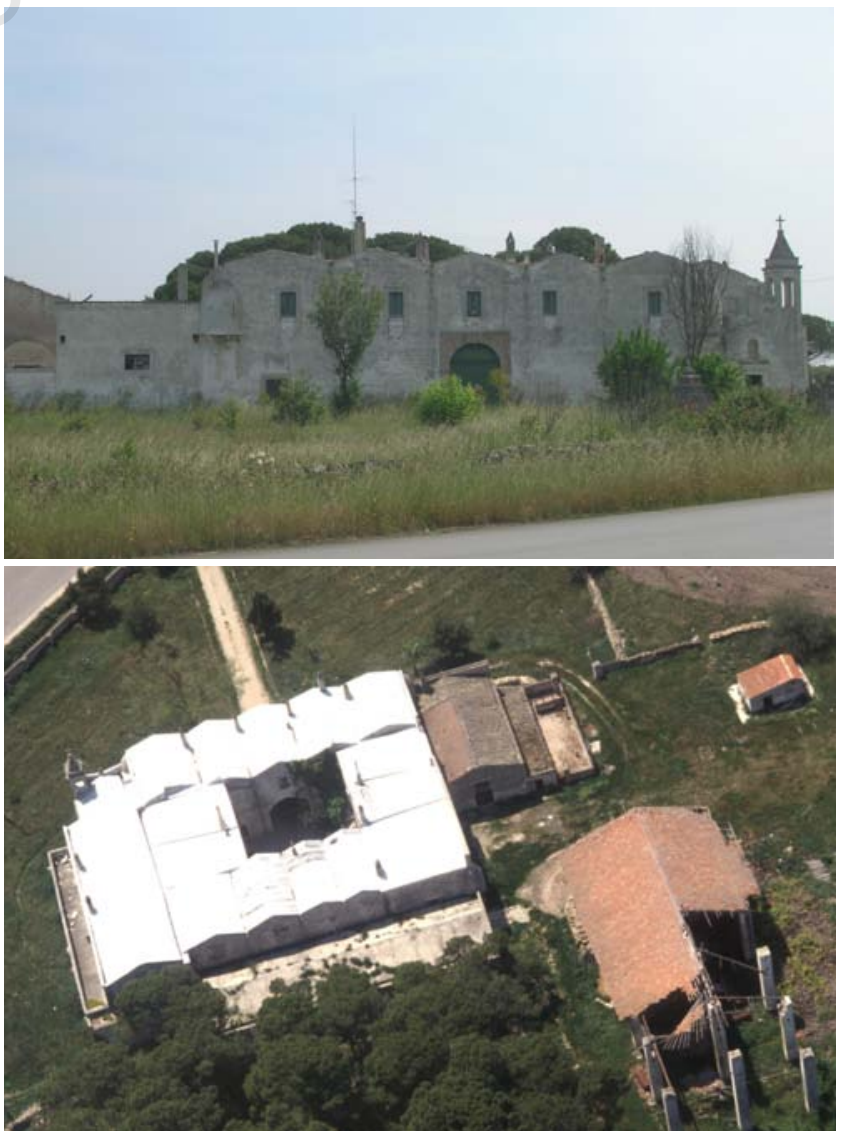

Figure 14. Masseria Viglione located in Matera. 
formation of surrounding housing rural towns, as in the case of the Palazzo di Scanzano farm at Scanzano Jonico (Figure 13), which overlooks a square around which rose the primordial village, consisting of small houses where the settlers lived. Built by Pedro de Toledo, it has been successively restored and used as a multifunctional building (it has also hosted the exhibition of the typical agro-food products from the Basilicata region). Numerous rooms on the ground floor lead off from the large yard of the country house. These are used as storage, and an internal staircases leads up to the rooms on the first floor. On top there is a small tower with a panoramic viewpoint and dovecote. On the two sides of the facade looking south there are two rows of houses standing next to each other, originally used as houses for the workers (casalini), as storage for tools and machinery, and as shelter for the livestock. In the center of the square (Figure 13), bounded by the palace, the casalini and the highway, there is a fountain that was built during the land reform.

Finally, among farms of composite structure, classified as specific forms of government, a special role was played by buildings that were devoted to agricultural activities, built as imposing structures that made them look like a fortified castle. This is the case of the Masseria Viglione (Figure 14), located along the road connecting Matera with the neighboring Apulia region, and the castle of St. Basilio (Figure 15), in the territory of Pisticci, which was built as a fortified farm by the monastic community of the Basilians, around the seventh century. Later on, it became a Norman feudal building, increasingly assuming the characteristics of a castle with the construction of the central tower. It was later donated by the Norman feudal lords to the community of Santa Maria di Pisticci. The complex is dominated by a large square tower, which dates back to the first half of the $11^{\text {th }}$ century, on top of which we can let our gaze sweep over a vast territory, including the entire line of the Gulf of Taranto. The main function of the tower was to control the coast assisted by the other neighboring towers, ready to raise the alarm in the event of the arrival of the Saracen pirates.

Another example of a fortified farm is the Torre Spagnola farm, in the territory of Matera (Figure 16). This is a building of great historical significance. It was built in early 1600 by Giuseppe Trullos de Myr, as documented by the praise given to it by the Spanish Viceroy Guzmán (on the lintel of the fireplace inside the house). It became the property of the Dominican friars in the 1700 s, and through the Napoleonic laws of 1806 the farm passed into the hands of the Marquis Ferrante di Ruffano. In 1888, it became the property of the Malvezzi family; then it passed into the hands of a new owner. Now it has been restored and is used for purposes of agricultural tourism.

\section{Discussion}

Today, after more than half a century, there have been no major changes regarding the rural buildings, apart from some minor interventions in reclaimed or irrigated areas. Most rural homes visited are not inhabited and the current survey showed a structural and functional degradation that in some cases has worsened over time. This makes renovation difficult, unless undertaken at the cost of complex and costly restructuring, such as in the case of the Jesce farm in the province of Matera (Figure 17).

In a period of growing interest in the traditional rural buildings for their recovery for cultural purposes, rural tourism activities, etc., a sound analysis aimed at assessing possible ways of recovery, depending on the deterioration of the building, the traditional vocation of the territory and the opportunities offered by the surrounding environment, becomes essential. Neither should their possible reuse for production purposes be underestimated (Dal Sasso and Caliandro, 2010; Fuentes et al., 2010). A recovery program of such a vast and important

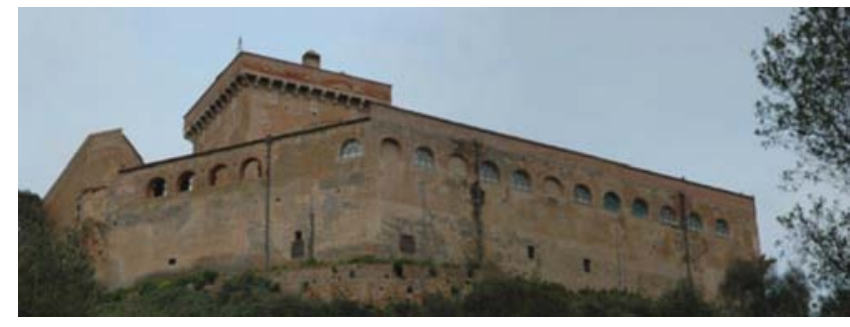

Figure 15. Castle-farm S. Basilio located in Pisticci.

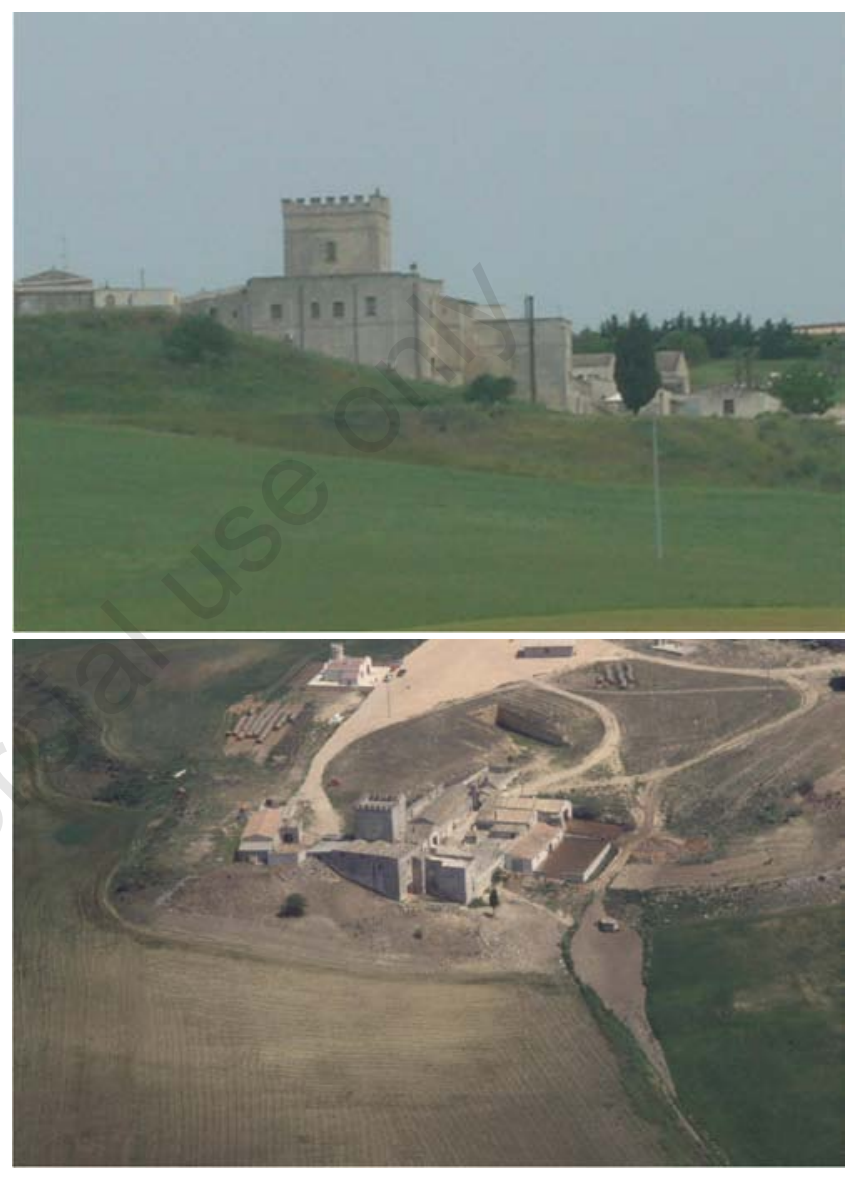

Figure 16. Masseria Torre Spagnola located in Matera.

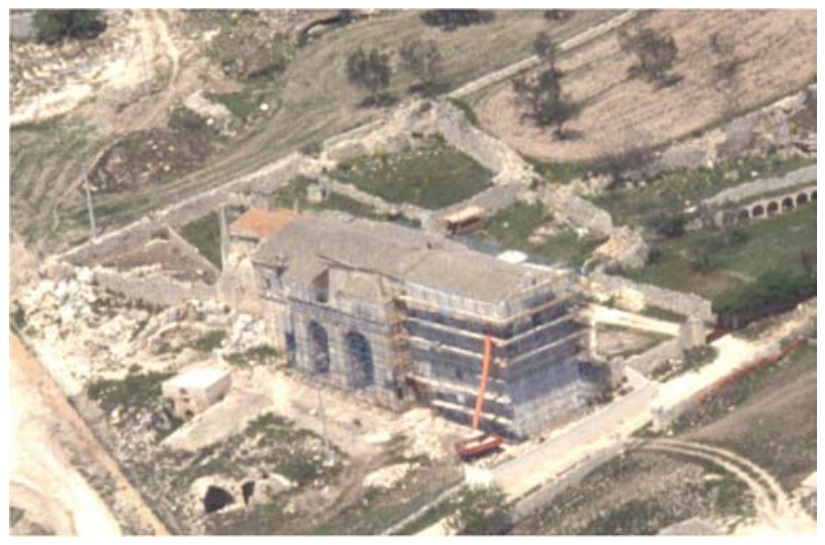

Figure 17. Works for restoring the Masseria Jesce located in the Province of Matera. 
heritage should begin with the systematic cataloguing of all types of lodgings all over the region (Fuentes, 2010; Fuentes et al., 2011).

Old buildings, like those built near the Ionian coastline that were progressively abandoned, are now facing a new lease of life because in an increasing number of cases they are bought by new owners (in some cases foreigners) who renovate them in order to use them as summer residences (thanks to their proximity to the sea), or as Albergo Diffuso (scattered hotels), a new way to attract tourists. This is a particular type of hotel conceived to provide guests with the unique experience of staying on a historical site. It provides all the services of traditional hotels (a host, assistance, common spaces, meals), but the rooms are scattered around the historical center and the heart of the hotel (the reception, the common spaces, the restaurant). The rooms and/or apartments are set within villas and apartments which, being part of the historical center, and being appropriately restored according to the local culture, immediately provide the feeling of being local. An Albergo Diffuso also represents a unique development approach which does not have a negative environmental impact. Nothing has to be newly constructed, since it is only necessary to restore and renovate existing houses and apartments according to the local cultural and historical backgrounds, and to network what there is already. Often it acts as the most relevant stakeholder in the territory, stimulating the local existing and potential entrepreneurs to create new businesses associated with the increased tourist demand that it brings, mainly in the most traditional sectors such as local gastronomy and handicrafts, for which Italy, and particularly the Basilicata region, are well known all over the world. It promotes and manages, together with local municipalities and the other existing actors, new activities capable of repositioning the territory on the tourist market, such as events including specific training courses in traditional sectors (local cuisine, local sports events, artisanship, etc.). In this way, new businesses are generated, in association with this new form of hospitality, that give visitors the experience of being temporary residents rather than traditional tourists. An Albergo Diffuso, in fact, thanks to the vicinity of the structures that compose it, and to the presence of a lively local community, offers acquaintance with a new lifestyle, rather than a period of pure holiday. This aspect alone is capable of generating enough economic turnover because it de-seasonalizes the demand contributing to the emergence of new tourist destinations that are usually off the beaten track (http://www.stratech.it/uploads/AlbergoDiffusoENG.pdf).

\section{Conclusions}

The rapid turnover of social models that occurred in the last century led to appreciable consequences on the heritage buildings in general, and especially in rural areas. The analysis that was carried out on the lodgings in Basilicata has revealed the existence of a number of types of architecture based on which the entire territory of the Basilicata region could be ideally divided. Most of the vernacular farm buildings, built over the past centuries, are also living witnesses of the wisdom of our forefathers to design buildings in a way that fosters natural components capable of maintaining optimal climatic conditions inside living quarters, where humans, animals and crops could find better conditions than in the open fields.

A classification of buildings of the region characterized by a higher degree of historical-cultural matrix has highlighted how some of them have a significant importance as evidence of the time passed and the social and cultural changes. The opportunity to restore some of them, by turning them into cultural containers, or for agricultural activities again, or for different forms of tourist facilities, seems to be worth pursuing in order to recover them in such a way as to balance the traditional vocation and environmental sustainability of the territory in which they are incorporated.
The typological analysis that was conducted, based on the main characteristics of the vernacular farm buildings (site altitude, meteorological conditions, local building materials, social tradition, etc.), has identified the main typologies of vernacular farm buildings spread all over the region, paving the way for the definition of a set of synthetic parameters for the assessment of their main morphological aspects. This typological analysis could, therefore, be used as a methodological tool to quantify this unique architectural heritage, and this should be the objective of future research. Useful hints derived from this typological analysis could also foster a more detailed design of new farm buildings, often designed based on industrial or urban models, with no ad hoc design research, thus leading to poor landscape compatibility and loss of economic opportunities for the agricultural sector.

\section{References}

Cañas I., Martín S. 2004. Recovery of Spanish vernacular construction as a model of bioclimatic architecture. Build. Environ. 39:1477-95.

Coch H. 1998. Bioclimatism in vernacular architecture. Renew. Sust. Energ. Rev. 2:67-87.

Dal Sasso P., Caliandro L.P. 2010. The role of historical agro-industrial buildings in the study of rural territory. Landscape Urban Plan. 96:146-62.

Franciosa L. 1942. La casa rurale nella Lucania. Ohlski, Firenze, Italy. [In Italian].

Fuentes J.M. 2010. Methodological bases for documenting and reusing vernacular farm architecture. J. Cult. Herit. 11:119-29.

Fuentes J.M., Gallego E., García A.I., Ayuga F. 2010. New uses for old traditional farm buildings: The case of the underground wine cellars in Spain. Land Use Policy. 27:738-48.

Fuentes J.M., Garcì A.I., Ayuga-Téllez E., Ayuga F. 2011. The development of the flour-milling industry in Spain: analysis of its historical evolution and architectural legacy. J. Hist. Geogr. 37:232-41.

García A.I., Ayuga F. 2007. Reuse of abandoned buildings and the rural landscape: the situation in Spain. T. ASABE. 50:1383-94.

García-Esparza J.A. 2010. Barracas on the Mediterranean coast. Int. J. Archit. Herit. 5:27-47.

Hernández J., García L., Ayuga F. 2004. Integration methodologies for visual impact assessment of rural buildings by geographic information systems. Biosyst. Eng. 88:255-263.

ISTAT (Italian National Institute for Statistics). 1991. $13^{\circ}$ Censimento generale della popolazione. ISTAT, Roma, Italy. [In Italian].

Labaki L.C., Kowaltowski D.C. 1998. Bioclimatic and vernacular design in Urban Settlements of Brazil. Build. Environ. 33:63-77.

Manera C., Minchilli M., Picuno P. 1990. L'abitazione rurale in Basilicata: analisi tipologica con metodologie fotogrammetriche. Proc. 2nd Seminar of the 2nd Section of AIGR (Italian Association of Agricultural Engineering), Città della Pieve, June 7-8, 1990, pp. 115-129. [In Italian]

Picuno P., Tortora A., Capobianco R.L. 2011. Analysis of plasticulture landscapes in Southern Italy through remote sensing and solid modelling techniques. Landscape Urban Plan. 100:45-56.

Ratti C., Raydan D., Steemers K. 2003. Building form and environmental performance: archetypes, analysis and an arid climate. Energ. Buildings. 35:49-59.

Singh K.M., Mahapatra S., Atreya S.K. 2009. Bioclimatism and vernacular architecture of north-east India. Build. Environ. 44: 878-88.

Van der Vaart J.H.P. 2005. Towards a new rural landscape: consequences of non-agricultural re-use of redundant farm buildings in Friesland. Landscape Urban Plan. 70:143-52.

Vissilia A.M. 2009. Evaluation of a sustainable Greek vernacular settlement and its landscape: Architectural typology and building physics. Build. Environ. 44:1095-106. 